\title{
Comparison of endoscopic resection techniques for duodenal neuroendocrine tumors: systematic review
}

\section{(ㄷ)(1) $\odot$}

\author{
Authors \\ Ricardo Vieira Botelho ${ }^{3}$ \\ Institutions \\ 1 Department of Endoscopy, Hospital 9 de Julho, São \\ Paulo, São Paulo, Brazil \\ 2 Department of Surgery, ABC Medical School, Santo \\ André, São Paulo, Brazil \\ 3 Department of Surgery, Hospital do Servidor Público \\ Estadual, São Paulo, São Paulo, Brazil
}

Helcio Pedrosa Brito ${ }^{1}$, Isabela Trindade Torres ${ }^{1}$, Karine Corcione Turke ${ }^{2}$, Artur Adolfo Parada ${ }^{1}$, Jaques Waisberg ${ }^{2,3}$,

submitted 14.9.2020

accepted after revision 29.3.2021

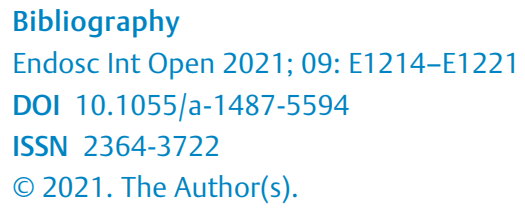
Commons Attribution-NonDerivative-NonCommercial License, permitting copying and reproduction so long as the original work is given appropriate credit. Contents may not be used for commercial purposes, or adapted, remixed, transformed or built upon. (https://creativecommons.org/licenses/by-nc-nd/4.0/)

Georg Thieme Verlag KG, Rüdigerstraße 14,

70469 Stuttgart, Germany

Corresponding author

Helcio Pedrosa Brito, Hospital Nove de Julho - Endoscopy, Peixoto Gomide Street, 545 São Paulo São Paulo 01409001, Brazil

Fax: +31479999

helciobrito@gmail.com
Background and study aims Regardless of size, duodenal neuroendocrine tumors (dNETs) should be considered potentially malignant. A complete resection without complications is essential to increase safety procedures. The aim of this review was to describe effectiveness and possible complications of endoscopic techniques resection for resectioning dNETs in patients with tumors $\leq 20 \mathrm{~mm}$ in diameter.

Methods An electronic bibliographic search was conducted using MEDLINE (via PubMed), Embase, Cochrane Central, and Google Scholar virtual databases. The types of intervention were endoscopic mucosal resection alone (EMR) or with cap (EMR-C), with a ligation device (EMR-L), with previous elevation of the tumor (EMR-I) or with endoscopic submucosal dissection (ESD); argon plasm coagulation (APC), and polypectomy. The outcome measures adopted were presence of free margin associated with tumor resection, tumor recurrence, complications (bleeding and perforation), and length of the procedure.

Results Ten publications were included with the result of 224 dNET resections. EMR alone and polypectomy resulted in the most significantly compromised margin. The most frequent complication was bleeding $(n=21)$, followed by perforation $(n=8)$. Recurrence occurred in 13 cases, the majority of those under EMR or EMR-I.

Conclusions EMR-C or EMR-I should be preferred for resectioning of dNETs. Polypectomy should not be indicated for resection of dNETs due to the high occurrence of incomplete resections. EMR alone must be avoided due a higher frequency of compromised margin and recurrent surgery. ESD was associated with no recurrence, however, but an increased occurrence of bleeding and perforation.

\section{ABSTRACT}

\section{Introduction}

Tumors limited to the submucosa of the duodenum, except for ampullary tumors, traditionally have been considered rare and not highly malignant, and according to previous reports, the incidence in autopsied cases is 0.02 to $0.5 \%[1,2]$. However, recent progress in endoscopic equipment, improvements in endoscopic techniques, and increased knowledge have gradually increased this incidence [3-5].

Duodenal neuroendocrine tumors (dNETs) are most commonly found on the first part of the duodenum, and their frequency progressively decreases toward its distal portions of it [2]. These tumors are usually solitary, small, restricted to the duodenal submucosa, and indolent, especially when they are 
small and limited to the submucosa, and the symptoms generally are unspecific [6-8].

Regardless of their size, gastrointestinal neuroendocrine tumors (GI-NETs) should be considered potentially malignant and require evaluation of the organ wall's involvement and the presence of metastasis. For primary dNETs, three independent risk factors for metastasis have been identified: invasion of the muscularis propria, tumor size $>20 \mathrm{~mm}$, and the presence of mitotic figures $[2,9]$.

Performing endoscopic ultrasound (EUS) before endoscopic resection improves the evaluation of the lesion in determining the extent of invasion, tumor size, and site of origin. It is used to decide the treatment approach (endoscopic or surgical) [3-5, 10-12]. Although the duodenum's anatomic characteristics make the endoscopic resection of duodenal lesions challenging, advanced endoscopic techniques exist that enable the resection of mucosal-based duodenal lesions. Two endoscopic treatment techniques for complete lesion removal limited to the organ wall's superficial layers without metastasis are endoscopic mucosal resection (EMR) and endoscopic submucosal dissection (ESD) [3-5]. Some professionals have reported using argon plasma for tumor ablation; however, its use is unusual and no studies exist with a large number of cases using the technique [13].

Five modalities of EMR are used for gastrointestinal neuroendocrine tumors (GI-NETs) with small dimensions $(\leq 20 \mathrm{~mm})$ in the absence of penetration of the muscularis propria and metastasis: snare-, underwater-, injection-, cap-, or ligation-assisted EMR. Compared with conventional polypectomy, EMR theoretically enables the resection of sufficient lateral margins for GI-NETs. Still, EMR cannot achieve a complete pathological resection for most GI-NETs that infiltrate into the deep submucosa; however, ESD can be performed for lesions considered unresectable by other endoscopic resection techniques $[13,14]$.

There is no agreement on the best endoscopic technique to resect dNETs. It is chosen at the examiner's discretion at the time of the procedure. Knowing the conditions under which each technique can offer a complete resection without complications is essential for increasing the procedure's safety. To the best of our knowledge, this is the first study to reveal published data comparing endoscopic techniques for dNET resection.

The aim of this study was to evaluate the effectiveness and possible complications of endoscopic dNET resection techniques in patients with tumors $\leq 20 \mathrm{~mm}$.

\section{Methods}

\section{Protocols and registration}

This systematic review was performed in accordance with the Preferred Reporting Items for Systematic Reviews and Metaanalyses (PRISMA) [15] recommendations And registered on PROSPERO (International Prospective Register of Systematic Reviews) Database (www.crd.york.ac.uk/prospero/) under number CRD42020192058.

\section{Eligibility criteria}

A literature search was based on structured questions, which defined the criteria for inclusion of papers, based on PICOT (Population of participants, Intervention and Comparison, Outcome measures and Types of studies) strategy. The types of participants were patients with $d N E T \leq 20 \mathrm{~mm}$. There were no restrictions regarding sex, age, risk factors, or symptoms in the study participants. The type of intervention was EMR alone and comparisons were EMR with cap (EMR-C), EMR with ligation device (EMR-L), EMR with previous elevation of the tumor (EMRI), ESD, argon plasma coagulation (APC) or polypectomy. The outcome measures adopted were the presence of free margin associated with tumor resection, tumor recurrence, complications (bleeding and perforation), and time of procedure.

Types of studies considered were any clinical studies (from randomized trials to single-arm cohorts) describing results on the outcomes of interest. Studies with less than 10 cases were excluded. There were no restrictions in terms of language or date of publication. Any type of study was used to retrieve the intervention complication, even case reports.

\section{Information sources}

To identify articles, searches were conducted using MEDLINE (via PubMed), EMBASE and Google Scholar. Databases were searched in August 2020.

\section{Search strategies}

The electronic literature search used were ((() ("carcinoid tumor" OR "carcinoid neoplasm"))) AND ((duodenum OR duodenal))) AND (("ligation assisted resection" OR “EMR ligation” $O R$ "endoscopic submucosal dissection" OR ESD OR EMR-L OR EMR infusion OR EMR-I OR EMR cap assisted OR EMR-C))) AND ((mucosectomy OR EMR OR endoscopic mucosal resection)).

\section{Study selection}

Articles were initially selected after an assessment of the titles and abstracts. Then, abstracts that did not fit the inclusion criteria were excluded. Selected papers were reviewed in full to identify those adequate to the defined selection criteria. Two independent reviewers (H.P.B. and I.T.T.) performed eligibility assessment and study selection. Disagreements between reviewers were resolved by consensus. Duplicated studies were removed.

\section{Data collection process}

The method of data extraction from each included study consisted of completing information sheets after the paper was evaluated. Relevant data were then extracted from each included study using a standardized extraction form. Both review authors extracted data from the included studies, and disagreements were resolved by discussion between the two review authors. There was no search for unpublished literature. Institutional review board consent was not required. 
- Table 1 Methodological index for non-randomized studies (MINORS) used to compare endoscopic resection technics for duodenal neuroendocrine tumors.

\begin{tabular}{|c|c|c|c|c|c|c|c|c|c|c|}
\hline Criteria & $\begin{array}{l}\text { Fujimoto } \\
\text { et al., } \\
2019 \\
{[17]}\end{array}$ & $\begin{array}{l}\text { Gincul } \\
\text { et al., } \\
2016 \\
{[22]}\end{array}$ & $\begin{array}{l}\text { Hatta } \\
\text { et al., } \\
2017 \\
{[23]}\end{array}$ & $\begin{array}{l}\text { Park } \\
\text { et al., } \\
2018 \\
{[24]}\end{array}$ & $\begin{array}{l}\text { Kim } \\
\text { et al., } \\
2013 \\
{[18]}\end{array}$ & $\begin{array}{l}\text { Mahmud } \\
\text { et al., } \\
2019 \\
{[25]}\end{array}$ & $\begin{array}{l}\text { Shroff } \\
\text { et al., } \\
2015 \\
{[19]}\end{array}$ & $\begin{array}{l}\text { Min } \\
\text { et al., } \\
2013 \\
{[13]}\end{array}$ & $\begin{array}{l}\text { Kim } \\
\text { et al., } \\
2014 \\
{[20]}\end{array}$ & $\begin{array}{l}\text { Oono } \\
\text { et al., } \\
2019 \\
{[21]}\end{array}$ \\
\hline A clearly stated aim & 2 & 2 & 2 & 2 & 1 & 2 & 2 & 2 & 2 & 2 \\
\hline Inclusion of consecutive patients & 2 & 2 & 2 & 2 & 2 & 2 & 2 & 2 & 2 & 2 \\
\hline Prospective collection of data & 2 & 1 & 2 & 2 & 2 & 2 & 2 & 2 & 2 & 2 \\
\hline $\begin{array}{l}\text { Endpoints appropriate to the } \\
\text { aim of the study }\end{array}$ & 2 & 2 & 2 & 2 & 2 & 2 & 2 & 2 & 2 & 2 \\
\hline $\begin{array}{l}\text { Unbiased assessment of the } \\
\text { study endpoint }\end{array}$ & 0 & 0 & 0 & 0 & 0 & 0 & 0 & 0 & 0 & 0 \\
\hline $\begin{array}{l}\text { Follow-up period appropriate } \\
\text { to the aim of the study }\end{array}$ & 1 & 2 & 2 & 2 & 1 & 2 & 1 & 2 & 1 & 1 \\
\hline Loss to follow-up less than $5 \%$ & 2 & 1 & 2 & 2 & 2 & 2 & 1 & 1 & 1 & 2 \\
\hline $\begin{array}{l}\text { Prospective calculation of the } \\
\text { study size }\end{array}$ & 0 & 0 & 0 & 0 & 0 & 0 & 0 & 0 & 0 & 0 \\
\hline $\begin{array}{l}\text { Additional criteria in the case } \\
\text { of comparative studies }\end{array}$ & - & - & - & - & - & - & - & - & - & - \\
\hline An adequate control group & - & - & - & 1 & - & 1 & - & - & 1 & \\
\hline Contemporary groups & - & - & - & 2 & - & 2 & - & - & 2 & - \\
\hline Baseline equivalence of groups & - & - & - & 1 & - & 1 & - & & 2 & - \\
\hline Adequate statistical analyses & - & - & - & 2 & - & -2 & - & - & 2 & - \\
\hline Total points & 11 & 10 & 12 & 18 & 10 & 18 & 10 & 11 & 17 & 11 \\
\hline
\end{tabular}

\section{Data items}

The selected data included age, gender, the total number of patients, study design, duodenal tumor size, duodenal site, treatment procedure type, procedure time, free margin, complication, follow-up, and recurrence.

\section{Summary measures}

Free margin, complications (bleeding or perforation) and recurrence were primary outcome measures and were collected and calculated using data provided from the original papers. Analysis was performed using EMR as the gold standard for dNET endoscopic resection.

\section{Risk of bias across studies}

All of the studies were retrospective in nature and had small patient samples. Some studies did not mention follow-up loss and the studies had different follow-up periods.

\section{Evaluation of methodological quality}

The methodological quality assessment was based on the Methodological Index for Non-Randomized Studies (MINORS) scale for non-randomized studies ( $>$ Table 1 ) $[15,16]$. The ranking considers noncomparative studies to have good methodological quality if a score of $\geq 12$ points is obtained; for compara- tive studies, a score of $\geq 18$ points should be reached. Some papers described separate results for tumors that could not be discriminated. We did not include these results to avoid confounding our observations.

Ten studies were single-arm cohorts and three compared different endoscopic resection techniques. There were no comparisons with placebo or other nonendoscopic techniques. Whether these studies were in fact comparative or only described single-arm results for two or more techniques is debatable.

In no study was sample size calculated to determine the number of patients necessary to ensure study power. All of the works described consecutive patients and established appropriate endpoints. The length of follow-up was appropriate in only five studies, The follow-up period was $>1$ year in five studies [17-21] and the follow-up length was $>2$ years in five studies [13, 22-25]. No study featured a blinded or double-blinded outcome analysis. Among the noncomparative studies, only one report scored 12 points or more. Among the comparative studies, two scored 18 points.

\section{Statistics}

Weighted medians or percentages for different outcomes were calculated based on the number of patients included in each study. 


\section{Records identified through database searching $(n=4589)$}

Records after duplicates removed $(n=2)(n=4587)$

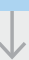

Titles and abstract screened $(n=36)$

Records excluded $(n=7)$

(Not about dNET)

Studies screened after reading the full-text $(n=29)$

Full-text articles excluded $(n=15)$

(Not about dNET)

Full-text articles assessed for eligibility $(n=14)$

Full-text articles excluded $(n=4)$

(Not enough cases)

Articles included in systematic review $(n=10)$

- Fig. 1 Preferred Reporting Items for Systematic Reviews (PRISMA) flow diagram for identified studies on resection of duodenal neuroendocrine tumor ( $\mathrm{dNet}$ ) with endoscopic techniques.

\section{Results}

\section{Study selection}

The search strategy (until August 11, 2020) resulted in 4589 articles. A total of 36 articles were selected by title. After analysis of the abstract, 29 papers were evaluated in full for eligibility. Fifteen papers were excluded and 14 articles were assessed for qualitative synthesis, with 10 publications remaining in the quantitative analysis (final data evaluation) ( $\triangleright$ Fig. 1).

\section{Study characteristics}

- Table 2 shows the characteristics of the studies and the data.

\section{Extraction of data}

- Table 2 provides detailed data from the evaluated studies.

\section{Pooled analysis: Margin involvement}

The capacity to obtain free margin involvement after tumor resection was assessed using 151 resections performed utilizing five techniques. The weighted proportion of free margin in all endoscopic cases was $59 \%$. The following techniques produced data related to the ability to produce free margins: EMR - Six papers described the resection of 83 tumors. The proportion of free margin in these cases was 54\%, ranging from 30 [25] to $100[13,20]$. Polypectomy - Only Mahmud et al. [25] evaluated the tumor-free margin in their study of 10 cases. They obtained only $10 \%$ of free margin. EMR-I - Three papers described results for 19 tumors, obtaining $71 \%$ of free margin (from $27 \%$ to $94 \%)$. EMR-L - Four papers described the resection of 36 tumors. The weighted rate of free margin was $69 \%$ (53\% to $82 \%$ ) $[17,19,20,24]$. APC - One study evaluated the free margin after using the APC technique [13], in which only three tumors were resected; the free margin was obtained from two of them (66\%).

\section{Recurrence}

Recurrence after tumor resection was analyzed in 92 resections utilizing 6 techniques. The weighted proportion of recurrence was $14 \%$. The data included the following techniques: EMR Hatta et al. [23] and Mahmud et al. [25] evaluated the resection of 52 tumors, with tumor recurrence of $13 \%$ and $3 \%$, respectively. The weighted proportion of recurrence was $8 \%$. Polypectomy - Only Mahmud et al. [25] evaluated recurrence after tumor resection by polypectomy in a study with 10 cases and a $10 \%$ recurrence rate. EMR-C - Only Shroff et al. [19] evaluated recurrence after tumor resection in a study with eight patients. The authors obtained a $25 \%$ recurrence rate. EMR-L - Shroff et al. [19] evaluated recurrence after tumor resection, in a study with three cases. The authors obtained a $33 \%$ recurrence rate. EMR-I - Two studies [19,22] evaluated the resection of 16 tumors ( 9 and 7 , respectively) and the respective recurrence rates were $22 \%$ and $29 \%$. APC - Only Min et al. [13] evaluated recurrence after tumor resection, in a study with three cases. The authors obtained a $33 \%$ recurrence rate.

\section{Bleeding}

Bleeding during tumor resection was assessed in 115 tumors resected using five techniques. The weighted bleeding rate was $18 \%$. The following techniques produced data related to the bleeding rate: EMR - Sixty-one tumors underwent EMR in four studies with an $11 \%$ pooled bleeding rate, ranging from $6 \%$ [20] to $25 \%$ [22]. The number of tumors treated with EMR in each study was eight, 12, 18, and 23. ESD - Two studies $[18,20]$ evaluated resection in nine tumors (5 and 4 tumors, respectively), with respective bleeding rates of $20 \%$ and $75 \%$. EMR-L - Fujimoto et al. [17] evaluated bleeding by tumor resection in a study with 10 cases. The authors obtained a $10 \%$ bleeding rate. EMR-I - Two studies [20,22] evaluated resection with EMR-I on 10 tumors ( 3 and 7, respectively), with respective bleeding percentages of $33 \%$ and $57 \%$. EMR-C - Twenty-five tumors underwent resection with EMR-C in two studies (12 and 13 , respectively) $[21,22]$. The bleeding percentages were $8 \%$ and $15 \%$, respectively.

\section{Perforation}

The perforation outcome was assessed using 55 resections done utilizing 4 techniques. The weighted proportion of perforation was $15 \%$ ( $8 \%$ to $33 \%$ ). The following techniques produced the data related to the possibility of perforation: EMR-L - Twenty tumors were resected, obtaining 15\% perforation in the pooled analysis, ranging from $10 \%$ to $33 \%[17,19,24]$. However, the number of cases submitted to resection was small, comprising three, seven, and 10 patients in each study. 
- Table 2 Data extraction from included studies used to compare endoscopic resection techniques for duodenal neuroendocrine tumors.

\begin{tabular}{|c|c|c|c|c|c|c|c|}
\hline Study & $\mathbf{N}$ & Procedure & $\begin{array}{l}\text { Length } \\
\text { (minutes) }\end{array}$ & $\begin{array}{l}\text { Compromised } \\
\text { margin }\end{array}$ & Complication & Recurrence & Study type \\
\hline \multirow{4}{*}{$\begin{array}{l}\text { Kim et al., } \\
2013\end{array}$} & \multirow[t]{4}{*}{12} & $5 \mathrm{ESD}$ & \multirow[t]{4}{*}{ N.A. } & \multirow[t]{4}{*}{ All negative } & 1 bleeding & \multirow[t]{4}{*}{ No } & \multirow{4}{*}{$\begin{array}{l}\text { Retrospective } \\
\text { Case series }\end{array}$} \\
\hline & & 3 EMR & & & - & & \\
\hline & & 3 EMR-L & & & - & & \\
\hline & & 1 EMR- C & & & - & & \\
\hline \multirow{2}{*}{$\begin{array}{l}\text { Park et al., } \\
2018\end{array}$} & \multirow[t]{2}{*}{15} & 7 EMR-L & 12,5 & 1 committed & 1 perforation & \multirow[t]{2}{*}{ N.A. } & \multirow[t]{2}{*}{ Retrospective } \\
\hline & & $8 \mathrm{EMR}$ & 9,2 & 5 committed & 1 bleeding & & \\
\hline $\begin{array}{l}\text { Fujimoto et } \\
\text { al., } 2019\end{array}$ & 10 & 10 EMR-L & N.A. & 4 committed & $\begin{array}{l}1 \text { bleeding } \\
1 \text { perforation }\end{array}$ & No & Retrospective \\
\hline \multirow{2}{*}{$\begin{array}{l}\text { Mahmud et } \\
\text { al., } 2019\end{array}$} & \multirow[t]{2}{*}{33} & 10 polypectomy & & 9 committed & - & 1 & \multirow{2}{*}{$\begin{array}{l}\text { Cohort Retro- } \\
\text { spective }\end{array}$} \\
\hline & & $23 \mathrm{EMR}$ & & 16 committed & 2 bleeding & 3 & \\
\hline \multirow{3}{*}{$\begin{array}{l}\text { Shroff et al., } \\
2015\end{array}$} & \multirow[t]{3}{*}{20} & 8 EMR-C & \multirow[t]{3}{*}{ N.A. } & - & - & 2 & \multirow[t]{3}{*}{ Prospective } \\
\hline & & 9 EMR-I & & 4 committed & 1 perforation & 2 & \\
\hline & & 3 EMR- L & & 2 committed & 1 perforation & 1 & \\
\hline \multirow{4}{*}{$\begin{array}{l}\text { Min et al., } \\
2013\end{array}$} & \multirow[t]{4}{*}{14} & 2 EMR-C & \multirow[t]{4}{*}{ N.A. } & - & \multirow{4}{*}{$\begin{array}{l}\text { ( } 2 \text { perforations in } \\
\text { procedures not } \\
\text { specified in the } \\
\text { text) }\end{array}$} & - & \multirow[t]{4}{*}{ Retrospective } \\
\hline & & 7 EMR-I & & - & & - & \\
\hline & & $3 \mathrm{APC}$ & & 1 commited & & 1 & \\
\hline & & $2 \mathrm{EMR}$ & & - & & - & \\
\hline \multirow{4}{*}{$\begin{array}{l}\text { Kim et al., } \\
2014\end{array}$} & \multirow[t]{4}{*}{41} & $4 \mathrm{ESD}$ & 33 & - & 3 bleeding & \multirow[t]{4}{*}{ No } & \multirow{4}{*}{$\begin{array}{l}\text { Retrospective } \\
\text { Multicenter }\end{array}$} \\
\hline & & 18 EMR & 13 & 10 committed & 1 bleeding & & \\
\hline & & 16 EMR-L & 14 & 4 committed & - & & \\
\hline & & 3 EMR-I & 18 & 1 committed & 1 bleeding & & \\
\hline \multirow{2}{*}{$\begin{array}{l}\text { Hatta et al., } \\
2017\end{array}$} & \multirow[t]{2}{*}{35} & $29 \mathrm{EMR}$ & \multirow[t]{2}{*}{ N.A. } & 9 committed & - & 1 & \multirow{2}{*}{$\begin{array}{l}\text { Retrospective } \\
\text { Multicenter }\end{array}$} \\
\hline & & $6 \mathrm{ESD}$ & & - & 2 perforations & - & \\
\hline \multirow{3}{*}{$\begin{array}{l}\text { Gincul et al., } \\
2016\end{array}$} & \multirow[t]{3}{*}{32} & 12 EMR & N.A. & (14 committed in & 3 bleeding & - & Retrospective \\
\hline & & 13 EMR-C & & $\begin{array}{l}\text { procedures not } \\
\text { specified in the } \\
\text { text) }\end{array}$ & $\begin{array}{l}2 \text { bleeding/ } 1 \text { per- } \\
\text { foration }\end{array}$ & - & \\
\hline & & 7 EMR-I & & & $\begin{array}{l}4 \text { bleeding/ per- } \\
\text { foration }\end{array}$ & 2 & \\
\hline $\begin{array}{l}\text { Oono et al., } \\
2019\end{array}$ & 12 & 12 EMR-C & $13(5-30)$ & N.A. & 1 bleeding & N.A. & Retrospective \\
\hline
\end{tabular}

EMR, endoscopic mucosal resection; EMR-L, endoscopic mucosal resection using ligation device; EMR-C, endoscopic mucosal resection using cap; EMR-I, endoscopic mucosal resection with previous submucosal elevation; ESD, endoscopic submucosal dissection; APC, argon plasm coagulation; N.A., not available.

ESD - Only Hatta et al. [23] evaluated perforation by tumor resection, in a study with six cases and $33 \%$ perforation. EMR-I Shroff et al. [19] and Gincul et al. [22] evaluated perforation during the resection of 9 and 7 tumors, with perforation rates of $11 \%$ and $14 \%$, respectively. EMR-C - Only Gincul et al. [22] evaluated perforation, in a study with 13 cases and an $8 \%$ perforation rate $(1 / 13)$.

\section{Length of procedures}

The length of procedures was evaluated in three studies [20, $21,24]$ using the following techniques: EMR $(n=26$, median time $=11.1$ minutes), EMR-L $(n=23$, median time $=13.2 \mathrm{~min}$ utes), EMR-I ( $n=3$, median time $=18$ minutes), EMR-C $(n=12$, median time $=13$ minutes $)$ and $\operatorname{ESD}(n=4$, median time $=33$ minutes). 


\section{Discussion}

dNETs are $<2 \%$ of GI-NETs and represent the least frequent primary tumor location [1, 2]. However, regardless of size, dNETs should be considered potentially malignant and require the evaluation of previous duodenal wall involvement and the presence of metastasis.

Although the articles used for this study did not differentiate NET subtypes or grade, both are important prognostic variables for neuroendocrine tumors from any site. Vanoli et al. [26] stated that ampullary-type somatostatin-producing NETs and gastrinomas show high local infiltration rates (especially lymphatic invasion and deep duodenal wall/pancreatic tissue invasion) and lymph node metastasis. In contrast, non-functioning GlNETs have significantly lower and more size-dependent, local invasive potential. Disease-specific survival differed significantly between NETs and neuroendocrine carcinomas, but not among NET subtypes. Poorly differentiated neuroendocrine carcinomas (NECs) are inevitably high grade and are associated with a poor prognosis [27].

Most dNETs are located in the first duodenal part (58\%) and descending duodenum (33\%). In comparison tumors located in the ampulla of Vater (approximately $20 \%$ ) are often considered separate entities due to their clinical behavior being more similar to that of pancreatic neoplasms. It has been reported that tumors arising from the periampullary area may have behavior that is more aggressive than that of tumors from other duodenal areas [28].

Performing EUS allows for better evaluation of the lesion before endoscopic resection, for determining the extent of invasion, tumor size, and site of origin and whether the endoscopic or surgical treatment approach should be chosen. EUS is quite accurate in differentiating the layers the gastrointestinal tract's wall and defining a tumor's layer of origin, it and may be useful for detecting blood vessels neighboring the neoplasm. Limitations of EUS include that differentiating malignant from benign lesions as well as definitive diagnosis still rely on pathological confirmation [5, 14]. The endoscopic findings (location, roughness, hardening), when associated with the characteristics detected by EUS (echogenicity, heterogeneity, and depth), are good predictive factors for the differential diagnosis of duodenal subepithelial and polypoid lesions [29]. Tumors can be found in any of the three layers. They are slightly hypoechoic and homogeneous, and EUS can help to determine whether a lesion can be safely resected by endoscopy or if surgical intervention is required [29]. Patients with invasion confined to the submucosa can be treated by mucosectomy, while those with evidence of deeper invasion can be treated with a surgical procedure. Varas et al. [30] reviewed 18 patients with 23 gastroenteropancreatic NETs and performed EUS before endoscopic resection to confirm the lesion's limited nature and the appropriateness of endoscopic resection for the lesion. They achieved results sensitivity of $94 \%$ in detecting appropriate candidates for endoscopic resection. Complete resection was achieved for $90.5 \%$ of the lesions. The current World Health Organization (WHO) classification system includes three grades (G1, G2, and G3) for NETs [31]. Tumor grade is assigned based on mito- ses per 10 high-power fields and by Ki-67 index. Low-grade tumors (G1) are those with $<2$ mitoses/10 high-power fields or $<3 \% \mathrm{Ki}-67$ index. Intermediate-grade tumors (G2) are those with two to 20 mitoses/10 high-power fields or $3 \%$ to $20 \% \mathrm{Ki}$ 67 index, and high-grade tumors (G3) have $>20$ mitoses/10 high-power fields or $>20 \% \mathrm{Ki}-67$ index. NECs are no longer graded because they are recognized to be uniformly high grade by definition, but they continue to be separated into small- and large-cell types [27, 31,32]. The European Neuroendocrine Tumor Society (ENETS) guidelines [33] propose tumor size $<1 \mathrm{~cm}$ as the cut-off diameter to identify tumors with more aggressive behavior deserving a radical resection and a more intensive follow-up program. EUS is suggested for these patients, to exclude tumor invasion and local nodal involvement.

The present study is the first to reveal published data comparing several endoscopic resection techniques for dNETs resection, to the best of our knowledge. Although any systematic review is aimed at evaluating randomized and multicenter comparative studies, there is a shortage of studies on the subject. All of the published articles were case reports with a small number of procedures, probably due to the rarity of this type of tumor.

This analysis evaluated the result of 224 dNET resections, seven endoscopic procedures, and four outcomes. Eight articles compared methods in a single cohort [13,18-20,22-25], and one was a multicentric study [20]. The resection techniques were chosen by the physician. There were 68 compromised margins among all of the resections. EMR resulted in the most significantly compromised margins, followed by EMR-L, and polypectomy. However, polypectomy had the largest number of compromised margins, followed by EMR, APC, and EMR-L, while ESD and EMR-C did not show any margin involvement. The analyzed articles did not relate the size or subtype of the tumor with the margin or involvement of recurrence. According to the ENETS guidelines, ampullary dNETs deserve surgical resection, regardless of the tumor size [6]. For nonampullary tumors, surgical resection is recommended for dNETs $>20 \mathrm{~mm}$ in diameter, and endoscopic removal is recommended for dNETs $<10 \mathrm{~mm}$ in diameter. For dNETs 10 to $20 \mathrm{~mm}$ in diameter, either endoscopic or surgical resection is allowed, on a case-by-case basis [32,33]. Panzuto et al. [28] suggested the possibility of conservative management for indolent sporadic dNETs with no periampullary site, that are well-differentiated, non-functioning, and $<10 \mathrm{~mm}$ in size. The behavior of dNETs varies depending on several factors, including the primary tumor site, size, grading, staging, and tumor burden, making this group of neoplasms extremely heterogeneous [28].

Untch et al. [27] concluded that tumor grade and tumor size were associated with recurrence-free survival in 75 patients who underwent EMR, local resection, or pancreaticoduodenectomy for dNETs. In their study, the average tumor size was $1.7 \pm 1.3 \mathrm{~cm}$, and $52 \%$ of patients had lymph nodes in their surgical specimen. The most common tumor grade was low (77\%) followed by high (14\%) and then intermediate (10\%). There were 11 tumor recurrences (either local or distant), and four patients died of their disease with a median follow-up of 27 
months. There were four recurrences of low-grade NETs, two recurrences of intermediate-grade NETs, and four recurrences of high-grade NECs. Comparison based on tumor grade revealed that a high-grade NECs were more likely to recur than low-grade duodenal NETs. While $29 \%$ of patients had recurrence in the intermediate-grade group, there was no statistical difference as compared to the low-grade group. Tumor size was more significant for the high-grade tumors than for low-grade tumors ( $2.6 \pm 1$ vs. $1.5 \pm 1.3 \mathrm{~cm}, P=0.02$ ); however, there were no differences in lymph node metastasis.

To Massinroni and Rossi [34], dNETs are heterogeneous tumors that can exhibit aggressive behavior with distant metastases, more frequently than previously described, needing complete initial staging before surgery endoscopic treatment to exclude distant metastasis, along with long-term follow-up after their resection.

In our study, the most frequent complication was bleeding $(n=21)$, all resolved by endoscopy, followed by perforation ( $n$ $=8$ ), of which three $(37 \%)$ required surgical intervention. Recurrence occurred in 13 cases, with the majority of those being under EMR alone or EMR-I, of which only two (15\%) cases resected by EMR alone required surgery. In general, the few complications were described concerning the total number of patients undergoing endoscopic resection, and most were resolved during the procedure.

Regarding the analysis performed in this study, there will always be concerns when analyzing observational studies in any systematic review because the results may be biased and feature both clinical and mathematical heterogeneity. In this study, all of the published data and their effects on outcomes are illustrated as is the amount of data available on this topic, revealing the existing body of evidence and the associated heterogeneity.

One major limitation of this study was that no randomized studies were evaluated. All of the evaluated studies were retrospective case series with small sample sizes. It is always desirable that the direction and magnitude of effects in published studies be shown. For relatively rare diseases, in the absence of randomized and comparative study results, any recommendation based on a small sample of patients should be considered with caution. Collaborative comparative studies with several techniques and sample sizes providing more significant should be encouraged.

\section{Conclusions}

Based on these results, despite being the least complicated procedure to be performed, polypectomy should not be used for resection of dNETs due to the high occurrence of incomplete resections. Among the mucosectomies, EMR-C or EMR-I should be preferred for resectioning dNETs, and EMR should be avoided; despite being the simplest procedure, it showed higher frequencies of compromised margin and recurrent surgery. ESD was not associated with recurrence but it was associated with a high occurrence of bleeding and perforation.

\section{Competing interests}

The authors declare that they have no conflict of interest.

\section{References}

[1] Ochiai Y, Kato M, Kiguchi Y et al. Current Status and challenges of endoscopic treatments for duodenal tumors. Digestion 2019; 99: 21 26

[2] Burke AP, Sobin LH, Federspiel BH et al. Carcinoid tumors of the duodenum. A clinicopathologic study of 99 cases. Arch Pathol Lab Med 1990; 114: 700-704

[3] Gaspar JP. Approach to the endoscopic resection of duodenal lesions. World J Gastroenterol 2016; 22: 600

[4] Sato Y, Hashimoto S, Mizuno K et al. Management of gastric and duodenal neuroendocrine tumors. World J Gastroenterol 2016; 22: 6817

[5] Scherübl H, Cadiot G. Early Gastroenteropancreatic Neuroendocrine tumors: endoscopic therapy and surveillance. Visc Med 2017; 33: 332-338

[6] Waisberg J, Joppert-Netto G, Vasconcellos C et al. Carcinoid tumor of the duodenum. Arq Gastroenterol 2013; 50: 3-9

[7] Waisberg DR, Fava AS, Martins LC et al. Colonic carcinoid tumors: a clinicopathologic study of 23 patients from a single institution. Arq Gastroenterol 2009; 46: 288-293

[8] Tsujimoto H, Ichikura T, Nagao $\mathrm{S}$ et al. Minimally invasive surgery for resection of duodenal carcinoid tumors: endoscopic full-thickness resection under laparoscopic observation. Surg Endosc 2010; 24: 471-475

[9] Boškoski I, Volkanovska A, Tringali A et al. Endoscopic resection for gastrointestinal neuroendocrine tumors. Expert Rev Gastroenterol Hepatol 2013; 7: 559-569

[10] Yamasaki Y, Uedo N, Takeuchi Y et al. Current status of endoscopic resection for superficial nonampullary duodenal epithelial tumors. Digestion 2018; 97: 45-51

[11] Rajan E, Wong Kee Song LM. Endoscopic full thickness resection. Gastroenterology 2018; 154: 1925-1937.e2

[12] Singh A, Siddiqui UD, Konda VJ et al. Safety and efficacy of EMR for sporadic, nonampullary duodenal adenomas: a single U.S. center experience (with video). Gastrointest Endosc 2016; 84: 700-708

[13] Min B-H, Kim ER, Lee JH et al. Management Strategy for small duodenal carcinoid tumors: does conservative management with close follow-up represent an alternative to endoscopic treatment. Digestion 2013; 87: 247-253

[14] Rösch T, Kapfer B, Will U et al. Accuracy of endoscopic ultrasonography in upper gastrointestinal submucosal lesions: a prospective multicenter study. Scand J Gastroenterol 2002; 37: 856-862

[15] Moher D, Liberati A, Tetzlaff J et al. Preferred reporting items for systematic reviews and meta-analyses: the PRISMA statement. PLoS Med 2009; 6: e1000097

[16] Slim K, Nini E, Forestier D et al. Methodological index for non-randomized studies (minors): development and validation of a new instrument. ANZ J Surg 2003; 73: 712-716

[17] Fujimoto A, Sasaki M, Goto O et al. Treatment Results of endoscopic mucosal resection with a ligation device for duodenal neuroendocrine tumors. Intern Med 2019; 58: 773-777

[18] Kim SH, Park CH, Ki HS et al. Endoscopic treatment of duodenal neuroendocrine tumors. Clin Endosc 2013; 46: 656 
[19] Shroff SR, Kushnir VM, Wani SB et al. Efficacy of endoscopic mucosal resection for management of small duodenal neuroendocrine tumors. Surg Laparosc Endosc Percutan Tech 2015; 25: e134-e139

[20] Kim GH, Kim JI, Jeon SW et al. Endoscopic resection for duodenal carcinoid tumors: A multicenter, retrospective study: Endoscopic resection of duodenal carcinoids. J Gastroenterol Hepatol 2014; 29: 318324

[21] Oono Y, Shinmura K, Hori K et al. Endoscopic submucosal resection using a ligation device without injection for duodenal neuroendocrine tumors. Surg Endosc 2019; 33: 2008-2014

[22] Gincul R, Ponchon T, Napoleon B et al. Endoscopic treatment of sporadic small duodenal and ampullary neuroendocrine tumors. Endoscopy 2016; 48: 979-986

[23] Hatta W, Koike T, lijima K et al. The risk factors for metastasis in nonampullary duodenal neuroendocrine tumors measuring $20 \mathrm{~mm}$ or less in diameter. Digestion 2017; 95: 201-209

[24] Park SB, Kang DH, Choi CW et al. Clinical outcomes of ligation-assisted endoscopic resection for duodenal neuroendocrine tumors. Medicine (Baltimore) 2018; 97: e0533

[25] Mahmud N, Tomizawa Y, Stashek KM et al. 1028 - Endoscopic Resection of duodenal carcinoid tumors: a single center comparison between simple polypectomy and endoscopic mucosal resection. Gastroenterology 2018; 154: 196-197

[26] Vanoli A, La Rosa S, Klersy C et al. Four Neuroendocrine tumor types and neuroendocrine carcinoma of the duodenum: analysis of 203 cases. Neuroendocrinology 2017; 104: 112-125
[27] Untch BR, Bonner KP, Roggin KK et al. Pathologic grade and tumor size are associated with recurrence-free survival in patients with duodenal neuroendocrine tumors. J Gastrointest Surg 2014; 18: 457-463

[28] Panzuto F, Massironi S, Partelli S et al. Gastro-entero-pancreatic neuroendocrine neoplasia: The rules for non-operative management. Surg Oncol 2020; 35: 141-148

[29] da Costa RD, Kemp R, do Santos JS et al. The role of conventional echoendoscopy (eus) in therapeutic decisions in patients with neuroendocrine gastrointestinal tumors. ABCD Arq Bras Cir Dig São Paulo 2020; 33: e1512

[30] Varas M], Gornals JB, Pons C et al. Usefulness of endoscopic ultrasonography (EUS) for selecting carcinoid tumors as candidates to endoscopic resection. Rev Esp Enfermedades Dig 2010: 102

[31] Nagtegaal ID, Odze RD, Klimstra D et al. The 2019 WHO classification of tumours of the digestive system. Histopathology 2020; 76: 182188

[32] Matsumoto S, Miyatani H, Yoshida Y. Endoscopic submucosal dissection for duodenal tumors: a single-center experience. Endoscopy 2012; 45: 136-137

[33] Delle Fave G, O’Toole D, Sundin A et al. ENETS Consensus Guidelines Update for Gastroduodenal Neuroendocrine Neoplasms. Neuroendocrinology 2016; 103: 119-124

[34] Massironi S, Rossi RE. ASO Author reflections: heterogeneity of duodenal neuroendocrine tumors. Ann Surg Oncol 2018; 25: 858-859 